\title{
Erratum
}

\section{Erratum to "Validity of Mental Workload Measures in a Driving Simulation Environment"}

\author{
Francesco Galante $\mathbb{D},{ }^{1}$ Fabrizio Bracco, ${ }^{2}$ Carlo Chiorri, ${ }^{2}$ Luigi Pariota $\mathbb{D}^{1}{ }^{1}$ \\ Luigi Biggiero, ${ }^{1}$ and Gennaro N. Bifulco ${ }^{1}{ }^{1}$ \\ ${ }^{1}$ Department of Civil, Architectural and Environmental Engineering, University of Naples Federico II, 80125 Naples, Italy \\ ${ }^{2}$ Department of Educational Sciences, University of Genoa, 16128 Genoa, Italy
}

Correspondence should be addressed to Luigi Pariota; luigi.pariota@unina.it

Received 26 September 2018; Accepted 30 September 2018; Published 5 November 2018

Copyright (c) 2018 Francesco Galante et al. This is an open access article distributed under the Creative Commons Attribution License, which permits unrestricted use, distribution, and reproduction in any medium, provided the original work is properly cited.

In the article titled "Validity of Mental Workload Measures in a Driving Simulation Environment" [1], the name of the fifth author was given incorrectly as Luigi Biggero. The author's name should have been written as Luigi Biggiero. The revised authors' list is shown above.

\section{References}

[1] F. Galante, F. Bracco, C. Chiorri, L. Pariota, L. Biggero, and G. N. Bifulco, "Validity of mental workload measures in a driving simulation environment," Journal of Advanced Transportation, vol. 2018, Article ID 5679151, 11 pages, 2018. 


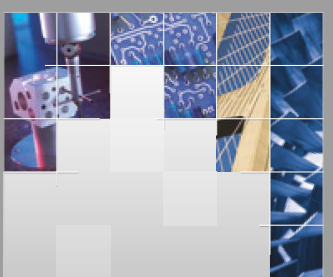

\section{Enfincering}
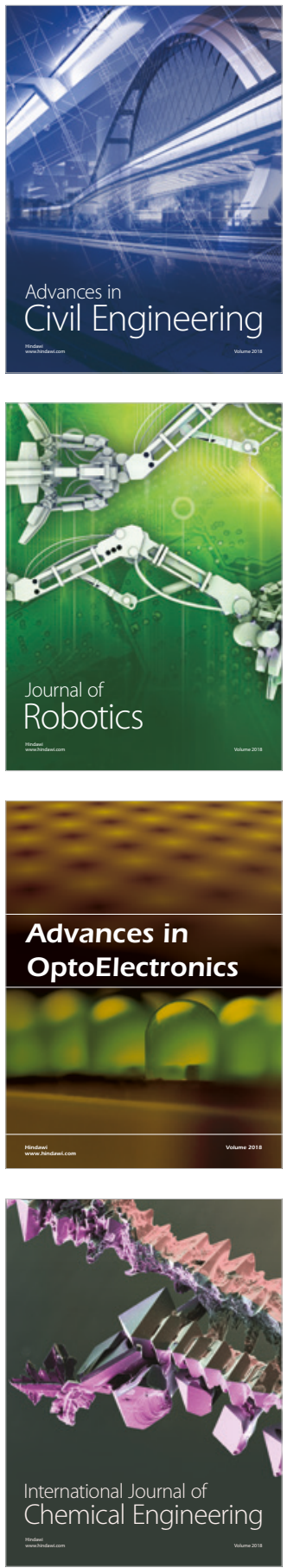

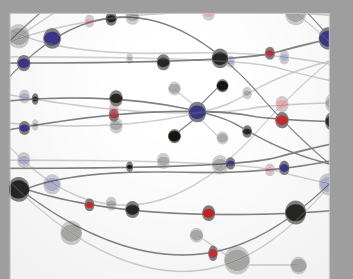

\section{Rotating \\ Machinery}

The Scientific World Journal

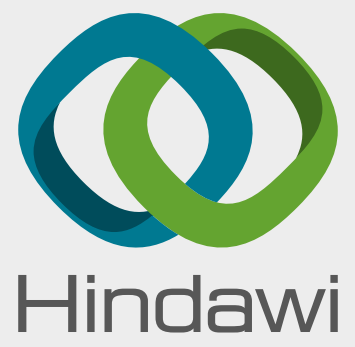

Submit your manuscripts at

www.hindawi.com
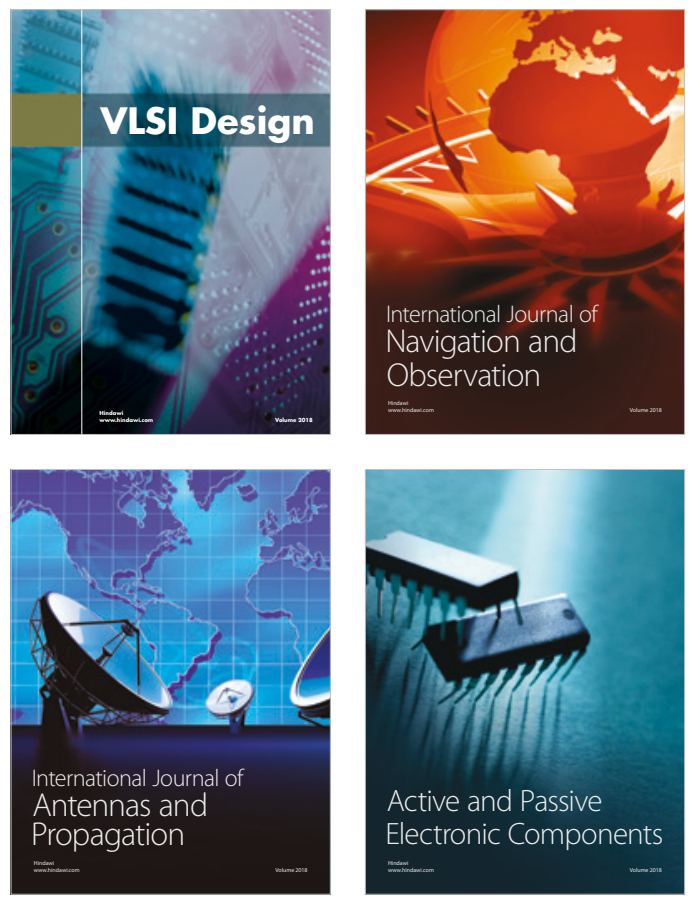
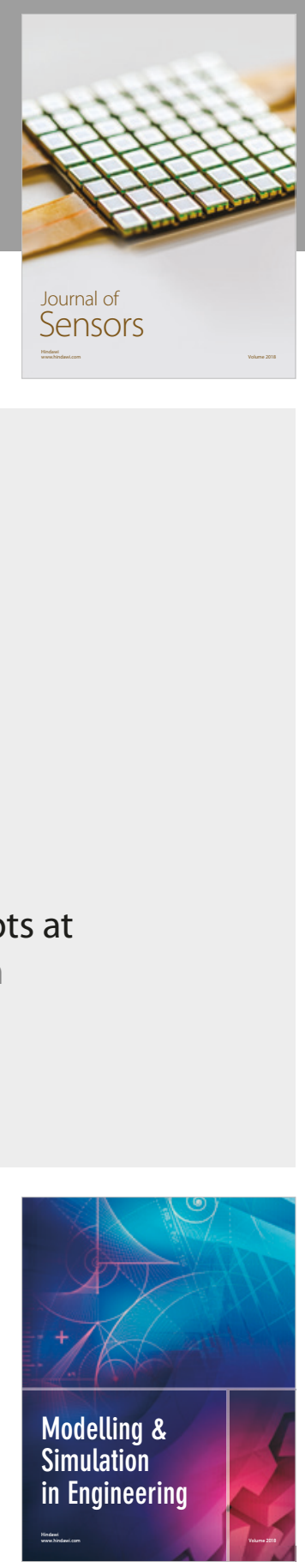

\section{Advances \\ Multimedia}
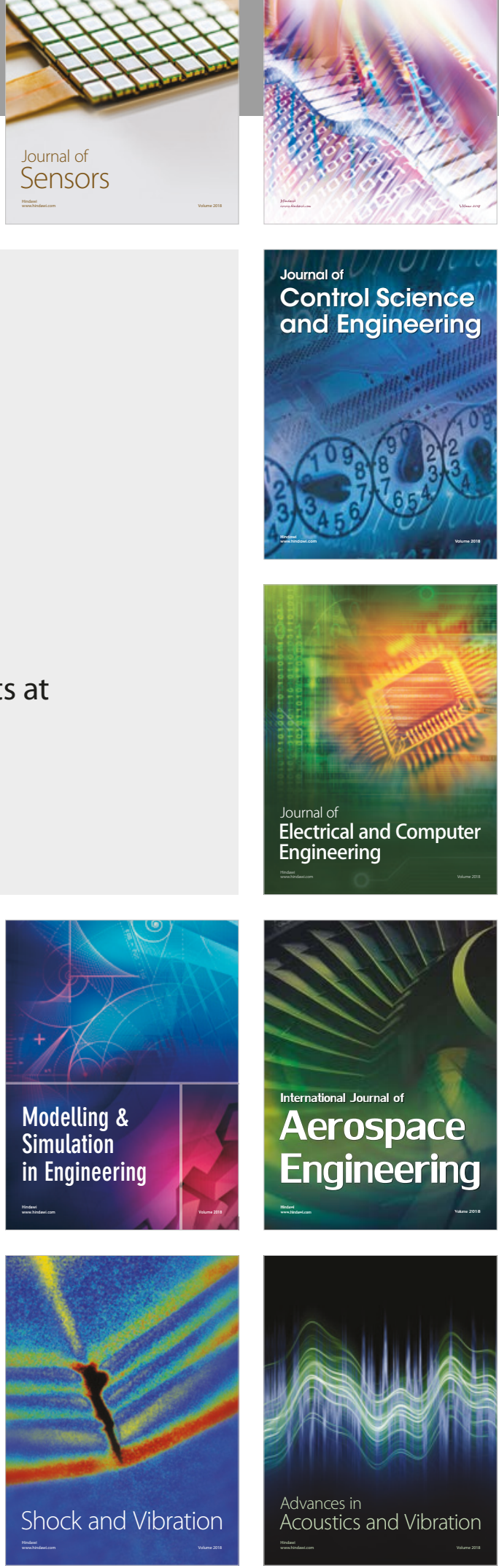